\title{
Inclusiveness in the Vocational Education Policy and Legal Frameworks of Kenya and Tanzania
}

\author{
Abebe Yehualawork Malle ${ }^{1}$ \\ ${ }^{1}$ Department of Education, University of Jyvaskyla, Finland \\ Correspondence: Abebe Yehualawork Malle, Department of Education, P.O Box 35, FI-40014, University of \\ Jyvaskyla, Finland. E-mail: abework2011@yahoo.com
}

Received: May 31, 2016

Accepted: June 20, 2016

Online Published: August 24, 2016

doi:10.5539/jel.v5n4p53

URL: http://dx.doi.org/10.5539/jel.v5n4p53

\begin{abstract}
This study examines the status of inclusiveness in the education and training policies of Ethiopia in comparison to those of selected East African countries. The focus is on vocational education in terms of the special educational and training needs of students with disabilities. Focus group discussions and interviews conducted in Kenya and Tanzania, relevant policy document analysis and the findings of Article 1 of the study were used as primary sources for the research. A total of 18 representatives of DPOs from Kenya and Tanzania participated in two sessions of focus group discussions, and 15 high-profile figures and experts from concerned government bodies of these study countries were interviewed. Most of the study participants agreed that the issue of disability was not adequately addressed in the education and training policies or the legal and implementation instruments of the study countries. The participants also proposed valuable recommendations.
\end{abstract}

Keywords: accessible environment, implementation instruments, inclusive education system, policy, special educational/training needs of students with disabilities, vocational education

\section{Introduction}

\subsection{Aims}

The main purpose of this study is to assess the status of inclusiveness in the vocational education and training policies and legal frameworks of Kenya and Tanzania regarding the special training needs and concerns of people with disabilities. Special attention was given to the participation of people with disabilities and their organisations in the preparation of the policy and legal frameworks. The findings are then compared with the situation in Ethiopia. Kenya and Tanzania were selected due to their geographical and socio cultural proximity to Ethiopia.

\subsection{Backgroud}

Effective vocational skills training is an essential prerequisite for the creation of a productive workforce that contributes to the socioeconomic development of a country. Technical and Vocational Education and Training (TVET) has been defined as developing ways of learning and the acquisition of attitudes that facilitate success in the workplace (Ngure, 2013). Training for the human workforce increases potential productivity and leads to the creation of new jobs as well as the improvement of the quality of products accepted by consumers in the market (Ngure, 2013). In Africa people with disabilities comprise a large part of the potential workforce. However, most African countries deny people with disabilities their inalienable right to employment, a barrier which presents a significant challenge for the development of these countries (Buckup, 2009).

In the last two decades, African nations have become aware of the typical role of TVET to meet the multifaceted economic needs of the people, including employability. As defined by African Union, "TVET delivery systems are well placed to train the skilled and entrepreneurial workforce that Africa needs to create wealth and emerge out of poverty" (African Union, 2007, p. 5). This emerging development in the sector of the TVET program is compatible with the vision of African Union, which is "an integrated, peaceful prosperous Africa driven by its own people to take its rightful place in the global community and the knowledge economy" (African Union, 2007, p. 5). The African Union has recognized TVET in the second decade of education as a means to economic empowerment and self-reliance of youths. 
As stated in the Plan of Action on the African Decade of Persons with Disabilities of 2010-2019, persons with disabilities belong to those underserved and overlooked groups who need priority of action/response from their respective governments and societies (African Union Commission Department of Social Affairs, 2010). The strategy of the African Union stresses the need to raise the productive capacity of all people, including vulnerable individuals, in order to lift them from poverty. As the document states, "The key to poverty alleviation is economic growth and the creation of employment for all. However, poor people without employable skills cannot benefit from the growth process. The challenge then is to raise the productive capacity of the poor, the youth and the vulnerable of society through the acquisition of job-specific competencies" (African Union, 2007, p. 18). A more recent document places an equal emphasis on vocational skills development as an important strategy to empower marginalized groups in a society by improving their livelihood while admitting the present deficiencies in this respect (African Union, 2014, p. 24).

The vocational education systems in Africa differ from country to country in their delivery and level of institutions. For instance, in sub-Saharan countries such as Kenya the formal TVET program is school based. In others it follows the colonial model, and students join TVET at the end of primary school (African Union, 2007).

\subsection{Overview of the Mission and Objectives of Vocational Education Programmes in the Study Countries}

\subsubsection{Kenya}

Despite the numerous challenges of the last two decades, the Development and Implementation of the Kenya Education Sector Support Program (2005-2010), the Ministry of Higher Education, Science and Technology Strategic Plan (2008) and the Science, Technology and Innovation Policy (2009) have enabled the country to achieve tremendous progress in the education and training sector in improving "access, equity, quality, relevance and sector management" (Godia, 2012, p. 4). The 2010 constitution of Kenya, article 10 section (2) (b) (c) and (d) set out the values that in the education and training sector the government should ensure the full participation of people, along with "equity, social justice, inclusiveness, equality, human rights, non-discrimination and the protection of marginalised groups, good governance, integrity, transparency and accountability and sustainable development" (Republic of Kenya, 2010, p. 15). Kenya enacted a TVET Act "which will conceive the Kenya TVET Authority by 2015" (African Union, 2014, p. 24). The overall goal of the vocational education policy of the government of Kenya was intended to "provide relevant and adequate skills for industrial and economic development" (Republic of Kenya, Ministry of Education, Higher Education, Science and Technology, 2012, p. 91). The promotion of inclusion of persons with disabilities in all sectors of society was one of the strategic thematic areas declared on the Continental Plan of Action for the Decade of Persons with Disabilities of 2010-2019. Under this thematic area, representation, education, livelihood, work, employment and so on were identified as priorities requiring special attention from governments (African Union Commission, Department of Social Affairs, 2010).

\subsubsection{Tanzania}

The concerted socioeconomic development effort of the government of Tanzania, guided by the Tanzania Development Vision 2025, recognised quality education and training as key instruments for the country (United Republic of Tanzania Planning Commission, n.d.). For the TVET sector, a five-year programme was developed. The programme focused on four priority areas, including access and equity, quality of outputs, capacity to provide quality TVET, and monitoring and evaluation (United Republic of Tanzania Ministry of Education and Vocational Training, 2013). The document further noted that the first priority area of the programme facilitates access to vocational education for students from disadvantaged groups. Alongside this TVET development programme, the Vocational Education and Training Authority of Tanzania developed a five-year Corporate Plan 2012/13-2016/17. In accordance with this guiding plan, the authority, as a responsible government agency, adopted a common vision on TVET development, stating that it should "ensure provision of quality VET that leads to generation of competitive labour force and contributes to social economic development" (United Republic of Tanzania Vocational Education and Training Authority, 2012).

\section{Method}

Three methods of data collection were used: document analysis of educational laws and statutes as they relate to disability issues in vocational training, interviews with key authorities in the field, and focus group discussions with persons working in disabled peoples' organisations in Kenya and Tanzania. The process of data collection was carried out according to the relevant legal procedures of the study countries by securing research permits from the Commission for Science and Technology (COSTECH) of Tanzania and the National Commission for Science, Technology and Innovation (NACOSTI) of Kenya. 


\subsection{Data Collection Procedures}

\subsubsection{Document Analysis}

Official documents from both countries were selected which focused on education and training policies, implementation/programmatic instruments and legal frameworks related to disability issues. The documents from Kenya referred to were: Persons with Disabilities Act of 2003, Kenya Vision 2030 of 2007, The National Special Needs Education Policy Framework of 2009, The Constitution of Kenya, Laws of Kenya of 2010, A Policy Framework for Education and Training of 2012, and Basic Education Act of 2013. The documents selected from Tanzania included: The National Policy on Disability of 2004, The Persons with Disabilities Act of 2010, The National Strategy on Inclusive Education 2009-2017 of 2010, Technical and Vocational Education and Training Development (TVETDP) 2013/14-2017/18 of 2013, The VETA Corporate Plan of 2012 and The Tanzania Development Vision 2025. These documents were analysed regarding their approach towards addressing the special educational and training needs of students with disabilities.

\subsubsection{Interviews}

Face-to-face interviews were conducted with eight informants from Kenya and seven informants from Tanzania. The participants were selected from education ministries, vocational education and training authorities and institutions - including TVET colleges and technical teachers training colleges-a national council for persons with disabilities, and the parliament of Kenya and Tanzania (see Table 1). The selection of informants was carried out using purposive and snowball sampling (Seidman, 2006) based on the relevance of their experience and current position in the ministries and institutions.

All interviews were held in the offices of the informants as per their choice, and a friendly approach was applied in order to probe the internal feelings and beliefs of the participants. The data were collected from the participants with their formal consent and any information they gave was kept confidential. In order to maintain the consistency and quality of the interview, guidelines were prepared and followed. Each interview lasted an average of one hour, and all interviews were recorded on a digital recorder with the consent of the informants. The interview guideline focused on the main objective of the research designed to assess the status of the inclusiveness of each country's respective education and training policy and legal documents.

\subsubsection{Focus Group Discussions}

The participants of the focus group discussions held separately in Kenya $(\mathrm{N}=9)$ and Tanzania $(\mathrm{N}=9)$ were representatives of disabled peoples' organisations. These organisations were members of national central organisations of the United Disabled Persons of Kenya (UDPK) or the Federation of DPOs of Tanzania. They represented several types of disabilities including visual and hearing impairment, physical disabilities, albinism, autism, and intellectual disabilities. Demographic data on the participants is presented in Table 1 . The high profile staff and leadership of these associations were selected based on their seniority and experience in the disability movements underway in the study countries.

A focus group discussion guideline was prepared and used to maintain the consistency of the discussion. The same procedure was used in both countries. Each discussion lasted an average of two-and-a-half hours. All focus group discussions were recorded using a digital recorder. Sign language interpreters and Kiswahili language translators were used to communicate, respectively, with hearing impaired participants and those who could not speak English.

\subsection{Data Analysis}

The document analysis, interview and focus group discussion guidelines were prepared focusing on the relevant thematic issues. The recorded interviews and focus group discussions were transcribed into hard copy of 75 pages. Based on the common pattern of data analysis strategy in qualitative research, three steps were employed: organising/preparing the data for analysis, describing/analysing the data, and interpreting the data (Marczyk et al., 2005).

The views gained from the data were organised and categorised in thematic areas focusing on the inclusivity of the education and training policies of the countries, the role of disabled peoples' organisations in the course of the preparation of the policies, and the practicality of these policies and relevant documents. The next phase of the analysis was to describe and analyse the findings. Finally, the results were interpreted. The findings of all three forms of data collection were combined in order to offer a multifaceted overall picture. 
Table 1. Profiles of the participants

\begin{tabular}{|c|c|c|}
\hline Characteristic & $\begin{array}{c}\text { Focus group } \\
\text { discussion } \\
(\mathbf{N}=\mathbf{1 8})\end{array}$ & $\begin{array}{c}\text { Interviews } \\
(\mathrm{N}=15)\end{array}$ \\
\hline \multicolumn{3}{|l|}{ Country } \\
\hline Kenya & 9 & 8 \\
\hline Tanzania & 9 & 7 \\
\hline \multicolumn{3}{|l|}{ Sex } \\
\hline Male & 12 & 13 \\
\hline Female & 6 & 2 \\
\hline \multicolumn{3}{|l|}{ Age } \\
\hline $18-30$ & 4 & - \\
\hline $31-45$ & 11 & 5 \\
\hline $46+$ & 3 & 10 \\
\hline \multicolumn{3}{|l|}{ Qualifications } \\
\hline Certificate & 3 & - \\
\hline Diploma & 4 & 1 \\
\hline Degree & 10 & 2 \\
\hline MA & 1 & 8 \\
\hline $\mathrm{PhD} / \mathrm{PhD}$ students & - & 4 \\
\hline \multicolumn{3}{|l|}{ Position } \\
\hline Managers & 3 & 1 \\
\hline Experts & - & 5 \\
\hline Lecturer/Trainer & - & 4 \\
\hline Parliamentarian & - & 1 \\
\hline High Government Profile & - & 3 \\
\hline Members of DPO Governance & 11 & 1 \\
\hline Parents of CWDs & 4 & - \\
\hline \multicolumn{3}{|l|}{ Work experience in years } \\
\hline $1-15$ & 8 & 5 \\
\hline $16-30$ & 8 & 6 \\
\hline $31+$ & 2 & 4 \\
\hline \multicolumn{3}{|l|}{ Types of impairment } \\
\hline Visual impairment & 1 & 5 \\
\hline Hearing impairment & 3 & - \\
\hline Physical impairment & 5 & - \\
\hline Albinism & 3 & 1 \\
\hline Others & 1 & - \\
\hline Non-disabled & 5 & 9 \\
\hline
\end{tabular}




\section{Findings}

\subsection{Document Analysis}

\subsubsection{Kenya}

Article 54 of the constitution of Kenya out laws discrimination on the basis of disability and provides specific articles in the Bill of Rights for Persons with Disabilities in terms of the provision of facilities, adaptive equipment and tools to address the educational and other special needs of persons with disabilities (Republic of Kenya, 2010). These include the use of sign language, braille or other appropriate means of communication, and access to assistive devices to overcome constraints arising from their impairments. Article 260 of the constitution defines the term disability, which had never happened before in the country's national law.

The 2003 Persons with Disability Act of Kenya laid the foundation for the realisation of the basic rights of persons with disabilities in the country. Article 18(1) of the Act enshrined that "no person or learning institution shall deny admission to a person with a disability to any course of study by reason only of such disability" (Republic of Kenya, 2003, p. 13). The Ministry of Education is implementing the National Special Needs Education Policy Framework (2009) targeting learners with physical, visual, hearing, speech and other impairments. This policy framework states that the Ministry of Education "shall recognise and reinforce inclusive education as one of the means for children with special needs to access education" (Republic of Kenya: Ministry of Education of Kenya, Science and Technology, 2012). Finally, the 2013 Basic Education Act of Kenya mainstreamed Articles that addresses the special educational needs of students with disabilities, including the availability of accessible infrastructure and relevant facilities (Republic of Kenya, 2013).

Moreover, the promotion of the participation of students with disabilities in general and vocational education programmes is included in the Vision 2030 document to which Kenya is committed (Republic of Kenya Vision 2030, 2007).

\subsubsection{Tanzania}

The National Policy on Disability was the earliest policy document that initiated disability-specific policy statements. This policy document declared the following: "The government in collaboration with stakeholders shall provide a conducive environment for inclusive education that takes care of special needs of disabled children" (United Republic of Tanzania, 2004, p. 16). The document further states: "The government in collaboration with stakeholders shall improve skills training and facilities for people with disabilities and skills training for people with disabilities will integrate the non-disabled trainees".

The principles and practices of inclusive education are also addressed in the National Strategy on Inclusive Education 2009-2017. The overall goal of this strategic document is that "all children, youth and adults in Tanzania have equitable access to quality education in inclusive settings" (United Republic of Ministry of Education and Vocational Training, 2013, p. 17). In accordance with Article 27(1) of the Disability Act of 2010, the government is committed to ensuring the educational and training needs of persons with disabilities throughout the regular education and vocational training system on an equal basis with others (United Republic of Tanzania National Assembly, 2010).

The Vocational Education and Training Authority of Tanzania, which is mandated to regulate the vocational education programme of the country, is authorised to develop strategies for mainstreaming cross-cutting issues such as gender and people with disabilities (Vocational Education and Training Authority, 2012). Based on the core strategic context of Technical and Vocational Education and Training Development Program (2013/14-2017/18), access and equity which have particular relevance to people with disabilities are recognised in the country's TVET programme as one of the priority areas (Ministry of Education and Vocational Education of United Republic of Tanzania, 2013).

\subsection{Focus Grup Discussions and Interviews}

\subsubsection{Awareness of Some Inclusive Policy Issues}

The interviewees and the participants of the focus group discussions of Kenya and Tanzania unanimously substantiated that they were aware of the inclusion of the special educational and training needs of students with disabilities in policy, legal and implementation instruments. The majority of the participants, however, specified that the specific needs of some impairments requiring special attention were not properly addressed in the documents. For example, the participants of the focus group discussion in Tanzania stated that the special needs of students with albinism, such as light protection devices for their eyes and lotion for their skin, was not taken into account and adequately included in the education and training policy statements. As a result, the specific 
needs of learners with albinism were not known to the majority of implementers of the policy. One participant from Kenya also argued that physical and psychosocial rehabilitation for autism and other severe impairments was not adequately included in the policy statements. The participants generally wanted more specific treatment of the needs of various disability groups in the documents and wished for more detailed sections on inclusive education and training. As one of the interviewees put it, "there is a room for being adequate".

Another interviewee from Tanzania argued differently, stating that as it is in other parts of the world, in Tanzania education and training were addressed as basic human rights as early as in the 1995 education and training policy of the country. As a result, the first Education Act of Tanzania of 2008 declared that every citizen has the right to access education. But these policy documents did not consider the special needs of learners with disabilities. He further added that the 2004 National Disability Policy of Tanzania included some phrases and statements calling upon the education system to respect the special needs of learners with disabilities at all levels, with an emphasis on the availability of adaptive learning materials, assistive devices and professionals trained in special needs education.

One interviewee from Tanzania stated that the endorsement of the Convention on the Rights of Persons with Disabilities paved the way for the development of the National Inclusive Education Strategy, but he added that there was no implementation mechanism. According to him, the government injected money for the implementation of inclusive education, but the allocated budget was not properly used to the extent of the existing needs. In addition, most teacher training colleges were not organized to train teachers in special needs education for inclusion.

\subsubsection{The Role of DPOs and Policy Makers}

The study participants from Kenya unanimously acknowledged that DPOs were facilitated to participate in the preparation of the education and training policy. However, among the eight interviewees, two high-profile government informants presented some critique. They said that the role and participation of DPOs was too limited to be able to enrich the policy documents appropriately. One of them described the relationship of DPOs and government as follows:

DPOs are usually activists in which their relation with the government might be sour. As a result, even though the situation has been changed after the foundation of the National Council for Persons with Disabilities, I believe that DPOs were not properly involved in the process of the preparation of the education and training policy of the country.

One interviewee argued that both DPOs and individual experts with disabilities were involved in the preparation of the constitution of Kenya of 2010. Persons with disabilities were consulted on contentious issues such as sign language.

All participants from Tanzania confirmed that there has been significant involvement of DPOs since 2004, when the National Policy on Disability was developed. It was from that policy onwards that the issue of inclusive education was raised. DPOs were also invited to offer their perspective when the National Strategy on Inclusive Education was being developed in 2009. However, the participants of the focus group discussion stated that the extent of the participation of DPOs was not as large as they expected. DPOs were often involved in the early stage of the preparation of policy and legal frameworks, but not later. The participants of the focus group discussion also experienced that in the final document most of the issues identified by DPOs were removed. One of the participants from the focus group noted that, in Tanzania, "DPOs were given the opportunity to be involved in the process of the preparation of the first draft of such policy and legal documents. But this kind of involvement of DPOs was nominal."

Most of the participants argued that policymakers cannot be fully aware of all fields and issues in society, such as disabilities. In a democratic society, policymakers should therefore facilitate the involvement and contribution of all citizens. Two interviewees working in the education ministries as experts, one from Tanzania and the other from Kenya, saw that DPOs were in a good position to advocate for the issue of disability and to influence policymakers because the constitution of these countries already included the issue of disability.

\subsubsection{Roots of Disability Policy}

Whether the inclusion of disability issues in education and vocational training policy was a home grown initiative was an issue of debate among the study participants. One of the interviewees from Kenya explained that after European colonisation it was difficult to distinguish what is a home grown initiative and what is a foreign one. Most of the study participants believed that the policies of the study countries could have been influenced by relevant international philosophy and trends, with one interviewee from Kenya stating: "I 
objectively believe that these policy documents might have been influenced by internationally recognised initiatives due to the fact that the world became a global village". He further justified his opinion that "learning is two ways, we could pick up practices from any other country, but it must be customised and suitable to the local context". An interviewee from Tanzania argued that persons with disabilities have engaged in a long and persistent struggle for the inclusion of disability issues in policy and legal frameworks. As an integral part of the international disability movement, the pressure of DPOs in Tanzania played a leading role as a home grown initiative in ensuring that the issue of disability is mainstreamed in relevant policy and legal instruments.

\subsubsection{Challenges and Opportunities}

Study participants were asked to identify the major challenges and opportunities as well as the way forward for the participation of persons with disabilities in vocational education. The participants agreed that the participation of students with disabilities in formal vocational education was insignificant. One Tanzanian interviewee pointed out that some efforts were made to facilitate the participation of students with disabilities in non-formal vocational training. However, no concrete progress has been made regarding the participation of students with disabilities in formal vocational education.

Most of the respondents identified the following factors as adversely affecting the participation of students with disabilities in formal vocational education:

1) The negative attitude of society and of the parents of children with disabilities in particular towards the potential and capacity of students with disabilities.

2) Lack of adapted and modified curriculum responsive to the special educational and training needs of students with disabilities.

3) Lack of specialised and adaptive equipment and technologies.

4) Lack of clear guidelines on the provision of adaptive skills and equipment such as sign language interpretation and assistive devices.

5) Lack of funding allocated for the promotion of inclusive education and training regardless of the availability of disability support allowance in Kenya.

6) Inaccessibility of the physical environment and accommodation services of vocational education centres and institutions.

7) Lack of proper integration of trainees with disabilities in the regular training system.

8) Lack of adequate technocrats trained in special needs education.

Regardless of these multifaceted challenges, most of the study participants recognised the following circumstances as opportunities for the enhancement of the participation of students with disabilities in regular vocational education programmes of the study countries:

1) The formulation of disability-mainstreamed and disability-specific policy, legal and implementation instruments.

2) The commencement and emergence of system change moving towards inclusive education and training.

3) The availability of political goodwill in the governments of the study countries.

Considering these challenges and opportunities, a majority of the study participants made the following recommendations on how to proceed with enhancing the participation of students with disabilities in vocational education:

1) Adapt and modify curriculum according to the special educational training needs of students with disabilities.

2) Mainstream special needs education as a common course in the curriculum of training programmes for trainers.

3) Carry out research on the issue of disability and vocational education.

4) Allocate adequate resources, paying proper attention to the special educational and training needs of students with disabilities.

5) Enhance the availability of specialised facilities, equipment, technology and assistive devices.

6) Make special funding available for alumni to be engaged in self-employment or income-generating activities through establishing their own enterprises upon the completion of their training. 
7) Conduct policy review and amend the national policy and legal documents with the objective of being more inclusive regarding the special educational and training needs and rights of people with disabilities.

8) Sensitise practitioners and communities regarding the basic as well as specific needs and rights of people with disabilities.

\section{Discussion}

This study investigated the status of inclusiveness in vocational education and training policies and practices in two African countries, Tanzania and Kenya, with a focus on the special educational and training needs of people with disabilities. Documentary analyses of relevant legislation and implementation instruments in both countries were supplemented by focus group discussions and interviews with key persons. Content analysis and thematic coding were used to analyse the material. The results showed that regardless of the prevailing drawbacks and limitations, some efforts were made in both Kenya and Tanzania to mainstream the special educational and training needs of persons with disabilities in relevant policy and legal instruments. However, the focus group participants representing, in particular, various Disabled Persons Organisations (DPOs) argued that the rehabilitation and specific needs of students with disabilities were not being properly addressed. In this case, the situation of Ethiopia is different than that of Kenya and Tanzania, where the special educational and training needs of people with disabilities was not properly and adequately addressed in the national education and training policy of the country (Malle, Pirttimaa, \& Saloviita, 2015b). On the basis of this lack, it can be inferred that in these countries policy revision is needed in order to make the statements compatible with the internationally accepted principles of special needs education.

The Continental Plan of Action for the Decade of Persons with Disabilities of 2010-2019 states that environment plays a significant role in facilitating and restricting the participation of persons with disabilities at the family, community and national levels. The widespread environmental barriers reported in this document include inadequate policies and standards, negative attitudes, lack of services, problems of service delivery, inadequate funding, lack of accessibility, lack of consultation and involvement, and lack of data and evidence (African Union Commission Department of Social Affairs, 2010). This document further states that member countries of the African Union are required to promote vocational education opportunity for people with disabilities, with a particular emphasis on marketable skills, by ratifying and implementing the ILO Convention No.159 concerning vocational rehabilitation and employment of persons with disabilities to ensure their entry into the labour market.

Regardless of the fact that the entire initiatives proposed by DPOs were not incorporated, most of the study participants from Kenya and Tanzania confirmed that DPOs were encouraged and invited to be involved in the process of preparing relevant education and training policy and legal frameworks. However, in the context of Ethiopia (Malle et al., 2015b), the participants reported that DPOs were not invited to take part in such consultative workshops and meetings. In addition, the high-profile interviewees also agreed that DPOs were not given the opportunity to participate in the process of preparing the policy. However, UN member countries are presently encouraged and required to enhance the role and participation of people with disabilities through DPOs as well as families, and to use their initiatives as valuable input for the development of disability-mainstreamed policy and legal instruments and standards (ILO, UNESCO, \& WHO, 2004).

The question of whether the inclusion of the special educational and training needs of people with disabilities was a home grown initiative or not remained debatable. Most of the participants from Kenya and Tanzania concurred that the policy development processes might have been influenced by internationally recognised philosophies and trends. In Ethiopia, the participants in the focus group discussions agreed that "the presence of the issue of disability in the 1994 Education and Training Policy was more or less the result of a donor-driven initiative" (Malle et al., 2015b). They stressed further that "if it had been a home-grown initiative, the country could have achieved more tangible change and progress in providing accessible educational and vocational training opportunities and facilities to persons with disabilities".

The results confirmed that the participation of students with disabilities in vocational education programmes in Kenya and Tanzania was insignificant due to their limited access to the services of TVET colleges. Similarly, attitudinal, environmental and institutional barriers were identified as predominant causes for the limited participation of people with disabilities in vocational education programme of Ethiopia (Malle, Pirttimaa, \& Saloviita, 2015a). It was argued that this affected the economy of the study countries in general and the lives of people with disabilities in particular. In line with the assessment conducted by ILO on the economic consequences of the exclusion of persons with disabilities, the GDP of Ethiopia and Tanzania lose 5.1 and 3.76 percent in each fiscal year respectively (Buckup, 2009). 
To sum up, a number of challenges that restricted the participation of students with disabilities in vocational education programmes of the study countries were identified by the respondents. The problems revolved around the non-availability of accessible service delivery and facilities as well as the inaccessibility of the physical environment in TVET institutions. In this respect, the Kenyan Ministry of Education and Ministry of Higher Education, Science and Technology (2012, p. 37) identified the main challenges that adversely affected the full and effective participation of students with disabilities in education and training, including "cultural prejudice and negative attitude, the slow implementation of guidelines on special needs education policy and inclusive education, inadequate data on the number of children with special needs, inadequate tools and skills for assessing and identifying learners with special needs, inadequate funding, inadequate facilities and teachers".

In this study, we found that the relevant policy, legal and implementation frameworks of the study countries regarding the special educational and training needs of persons with disabilities did identify the major obstacles hampering participation in vocational education programmes. However, regardless of the political goodwill observed on the part of the governments of the study countries, including Ethiopia, the commitment to the implementation of those disability-mainstreamed policy and legal instruments remains limited. This limitation continues to adversely affect the educational and training rights of persons with disabilities as well as their full and effective participation in the regular vocational education systems.

\section{References}

African Union. (2007, May). Strategy to revitalise technical and vocational education and training (TVET) in Africa. Meeting of the Bureau of the Conference of Ministers of Education of the African Union (COMEDAF II + ), Addis Ababa, Ethiopia. Retrieved from http://info.worldbank.org/etools/docs/library/243614/TVET\%20Strategy\%20in\%20Africa.pdf

African Union. (2014). AU outlook on education report: East African Community (EAC). Cameroun: Author. Retrieved from http://www.adeanet.org/sites/default/files/au_outlook_report_eac_english_version 2014_web.pdf

African Union Commission Department of Social Affairs. (2010). African Union Continental Plan of Action for the African Decade of Persons with Disabilities, 2010-2019. Retrieved from http://sa.au.int/en/sites/default/files/CPoA\%20Handbook\%20\%20AUDP\%20English\%20-\%20Copy.pdf

Buckup, S. (2009). The price of exclusion: The economic consequences of excluding people with disabilities from the world of work. International Labour Office (ILO), Employment Sector, Employment working Paper No. 43. Geneva: Author.

Godia, G. I. (2012, September). Kenya, a nation in transition. Opportunities and constraints, alignment of education center to the new constitution. Paper presented in the 5th Annual Conference of the Kenya Scholars \& Studies Association. Retrieved from $\mathrm{http} / / / \mathrm{kessa}$. org/yahoo_site_admin/assets/docs/5TH_ANNUAL_CONFERENCE_PAPER_keynoteaddress. 25190110.pdf

ILO, UNESCO, \& WHO. (2004). CBR: A strategy for rehabilitation, equalisation of opportunities, poverty reduction and social inclusion of people with disabilities, Joint Position Paper. United Nations: Author. Retrieved from http://apps.who.int/iris/bitstream/10665/43060/1/9241592389_eng.pdf

Malle, Y. A., Pirttimaa, R., \& Saloviita, T. (2015a). Inclusion of Students with Disabilities in Formal Vocational Education Programs in Ethiopia. International Journal of Special Education, 30(2), 1-10.

Malle, A., Pirttimaa, R., \& Saloviita, T. (2015b). Policy-practice gap in participation of students with disabilities in the education and training programme of Ethiopia: Policy content analysis. Support for Learning, 30(2), 121-133. http://dx.doi.org/10.1111/1467-9604.12084

Marczyk, G., DeMatteo, D., \& Festinger, D. (2005). Essentials of research design and methodology. New Jersey: John Wiley \& Sons.

Ngure, S. W. (2013). Where to vocational education in Kenya? Is analysing training and development needs the answer to the challenges in this sector? Journal of Education and Vocational Research, 4(6), 193-204.

Republic of Kenya. (2003). Persons with disabilities act. Nairobi: Author.

Republic of Kenya. (2007). Kenya vision 2030. Nairobi: Author. Retrieved from http://theredddesk.org/sites/default/files/vision_2030_brochure_july_2007.pdf 
Republic of Kenya Ministry of Education. (2009). The national special needs education policy framework. Nairobi: Author.

Republic of Kenya. (2010). Constitution of Kenya. Laws of Kenya, Amkeni wakenya, Nairobi: Author.

Republic of Kenya Ministry of Education and Ministry of Higher Education, Science Technology. (2012). Sessional paper: A Policy framework for education and training. Reforming education and training in Kenya. Nairobi: Author.

Republic of Kenya. (2013). The basic education act. Nairobi: Author.

Seidman, I. (2006). Interviewing as qualitative research. A guide for researchers in education and the social sciences (3rd ed.). New York: Teacher Collage Press.

United Republic of Tanzania Ministry of Labor, Youth Development and Sports. (2004). The national policy on disability. Dar es Salaam: Author.

United Republic of Tanzania Ministry of Education and Vocational Training. (2010). National strategy on inclusive education (2009-2017). Final Draft. Dar es Salaam: Author.

United Republic of Tanzania National Assembly. (2010). The persons with disabilities act. Dar es Salaam: Author.

United Republic of Tanzania. Vocational Education Training Authority (VETA). (2012). VETA corporate plan 2012/13-2016/17. Dar es Salaam: Author.

United Republic of Tanzania Ministry of Education and Vocational Training. (2013). Technical and vocational education and training development program (TVETDP) 2013/14-2017/18. Ministry of Education Press “A” Magogoni Road, Dar es Salaam: Author.

United Republic of Tanzania Planning commission. (n.d.). The Tanzania development vision 2025. Retrieved from http://www.tzonline.org/pdf/theTanzaniadevelopmentvision.pdf

\section{Copyrights}

Copyright for this article is retained by the author, with first publication rights granted to the journal.

This is an open-access article distributed under the terms and conditions of the Creative Commons Attribution license (http://creativecommons.org/licenses/by/4.0/). 